\title{
Study on Seismic Behavior for Viscous energy dissipation brace Concrete Frame Joints
}

\author{
Longlin RAN ${ }^{1,}$, , Wenhong HOU ${ }^{1, b}$, Huitie LIU ${ }^{1}$, Jinli QIAO ${ }^{2}$, Shuang HOU \\ ${ }^{1}$ Tianjin NO.2 Construction Engineering co., Ltd, Tianjin, 300141, China \\ ${ }^{2}$ School of Civil Engineering, Hebei University of Technology, Tianjin, 300132, China \\ aranlonglin@126.com, bhwh_20031105@163.com
}

\begin{abstract}
Keywords: Viscous Damper; Concrete Frame Joints; Seismic Performance
Abstract. In order to study the effect of viscous energy dissipation brace to the special Stress Performance of the concrete frame joint, the paper analyzes the concrete frame with installed and not installed damper under the action of earthquake by adopting Sap2000. The internal forces in joint area and seismic capacity of concrete frame are compared. The analysis results prove that installed this damper improves the ability of joint's energy consumption, and produces stress concentration in joint area. But internal forces are improved, and the story drift angle of floor displacement and floor shear are significantly reduced. The seismic capacity of concrete frame are obviously improved and improve the seismic performance of structure.
\end{abstract}

\section{Introduction}

In order to study the effect of energy dissipation device to the concrete frame joint, Morgen B et al have studied a new rotation of friction energy dissipator being set in the prestress reinforced concrete beam-column joints, and done large size prefabricated component tests, the result shows that the energy dissipator can dissipate a large number of earthquake energy and protect the security of the main structure [1]. Zhou Yun et al have studied axillary viscous damper brace in influence on frame structure, and found that the internal force of beam-column joint significantly has been reduced setting the viscous damper brace, the emergence and development of plastic hinge delayed on the framework pillars, the beam-column joints effectively protected, the seismic performance of reinforced concrete frame improved[2]. Cui Mingjuan et al analyzed the influence on frame joint for a new type of steel tank damper, through the analysis of the finite element software ABAQUS, the damper is effective improving the hysteretic performance of beam-column joints, and advantageous to the seismic[3]. Besides, there are a lot of research results[4,5]. In order to further study on seismic behavior for viscous energy dissipation brace concrete frame joints, no control structure and control structure is analyzed respectively basing on the finite element software sap2000.

\section{Theoretical Analysis of the Energy Dissipation Damping Mechanism}

Maxwell model that is the viscous damper mechanical model for damping in series with the spring units is adopted in this paper. The viscous damping unit in Sap2000 as shown in figure 1.

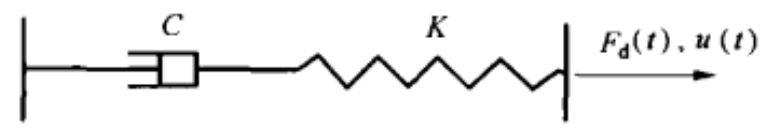

Fig 1 Maxwell Model

Assuming that axial deformation of damping unit and spring unit respectively are $d_{k}$ and $d_{c}$.

$d=d_{k}+d_{c}$

$f_{d}=k d_{k}=C d_{c}^{E x p}$

$k$ represent the spring constant; $C$ represent damping coefficient; Exp represent damping 
index, must be positive; the scope of use is between $0.2 \sim 2.0 ; d_{k}$ represent the deformation in the damper; $d_{c}$ represent the deformation rate in the damping.

\section{Numerical Model}

A four stories RC frame is simulated and analyzed to nonlinear time history using sap2000 for not installed damper, each story installed dampers, the following two layers installed dampers and the above two layers installed dampers, the analysis model is shown in figure 1 . The viscous damper is simulated by Nlink element in sap2000. Damping coefficient $C \alpha=1000 \mathrm{kN} \cdot \mathrm{s} / \mathrm{m}$, Speed index $\alpha=0.2$, Stiffness coefficient is 100 10000 times of damping coefficient in the structure [6].

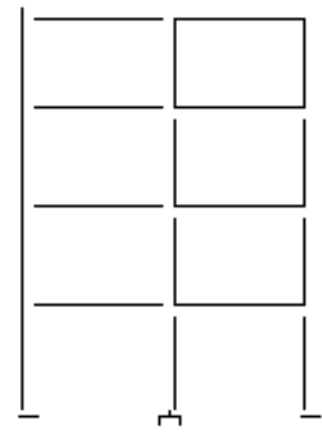

crįg̣intis slux:lure:

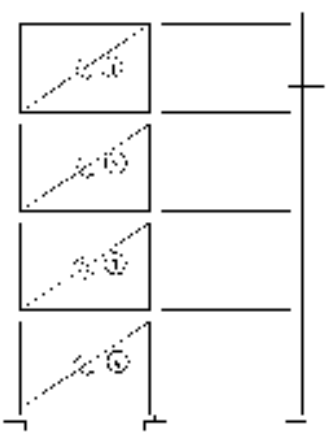

rmetd:y 1

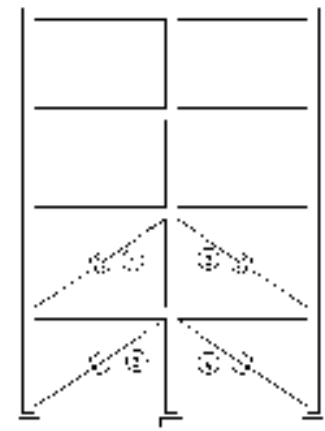

rmade! 7

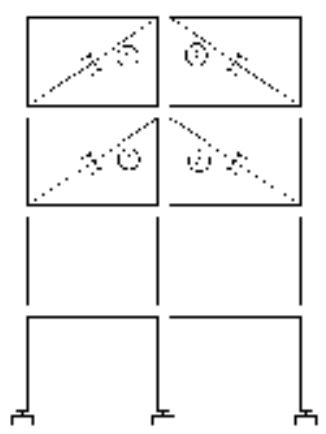

meded?

Fig 2 Calculation model

When nonlinear time history in the structure is analyzed using sap2000, El Centro - wave (peak $341.7 \mathrm{~cm} / \mathrm{s} 2$ ) of $70 \mathrm{Gal}$ (more than 8 degrees met earthquake) is used, sampling period is $0.02 \mathrm{~s}$. The results of the analysis as shown in the following Fig 2- Fig 4.
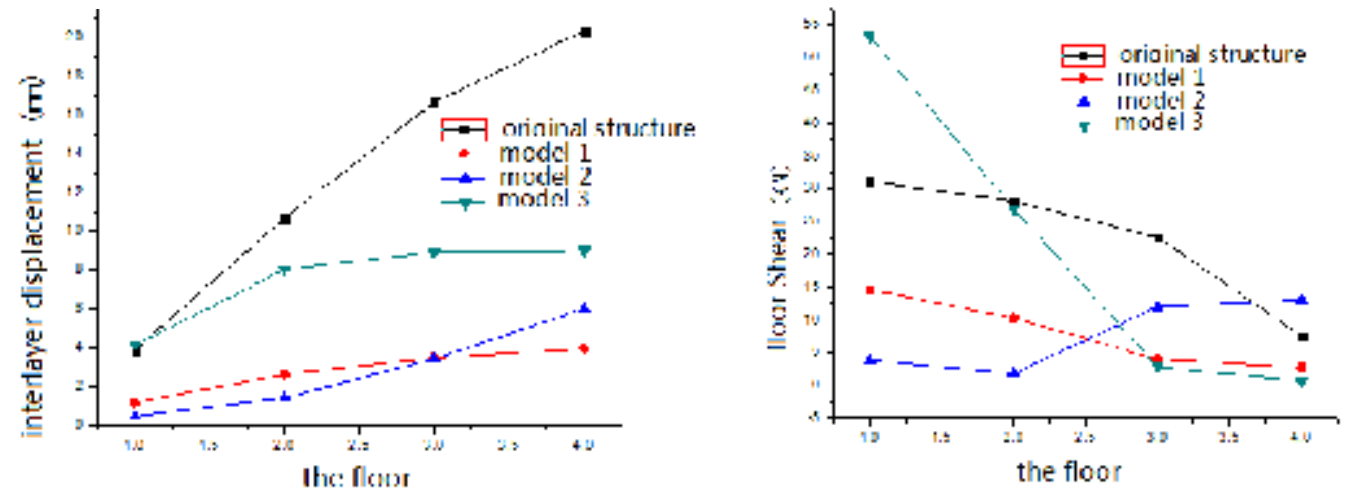

Fig 3 the interlayer displacement and floor shear under more earthquake of El-Centro wave in X direction 


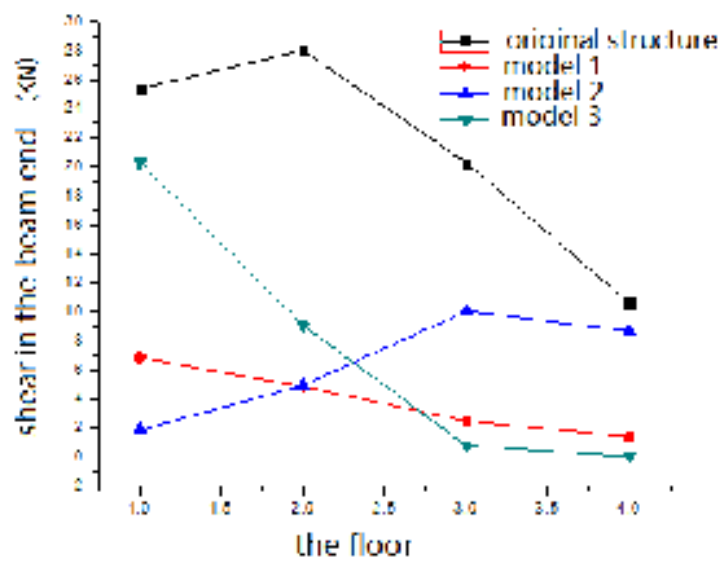

Fig 4 the shear of beam end in middle column joint

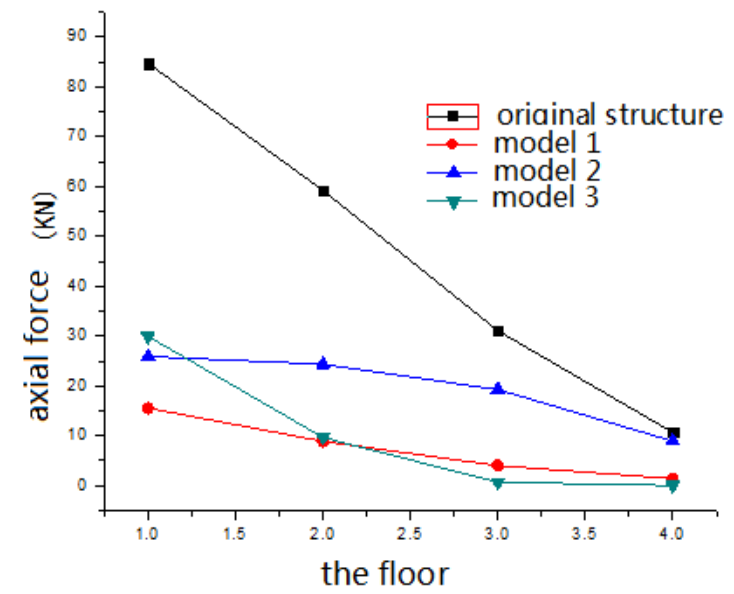

Fig 5 axial force of the side column

Table 1 the axial force of viscous damper

\begin{tabular}{|c|c|c|c|}
\hline $\begin{array}{c}\text { number of viscous } \\
\text { damper }\end{array}$ & Model 1 (KN) & Model 2(KN) & Model 3(KN) \\
\hline 1 & 37.91 & 50.76 & 4.33 \\
\hline 2 & 68.71 & 75.46 & 5.13 \\
\hline 3 & 117.77 & 29.84 & 69.65 \\
\hline 4 & 95.87 & 38.48 & 70.95 \\
\hline
\end{tabular}

By contrast, the interlayer displacement, angular displacement and interlayer shear force is significantly reduced on each floor of frame structure being installed viscous damper, decreases rate of maximum displacement in the seismic of the structure is the maximum to $80.5 \%$ in the $\mathrm{X}$ direction, it is obvious to improve the seismic performance of the structure. The contrast of the model one, two and three can be found that the seismic capacity of the frame structure with viscous dampers is better in model 1 . The seismic capacity of the frame structure have improved in the model two and three because of each floor being installed the viscous damper, but the structure is easy to be destroyed because larger stress is generated in the floor of not installed the viscous damper. Because of the energy dissipation of the damper, the axial force in the viscous damper and the stress concentration in the joint are obviously generated. However, the shear force and axial force at the joint of the beam and the column end installed the viscous damper are obviously decreased, which indicates that the viscous damper can improve the structural mechanical proprieties and reach the requirement of earthquake by viscous energy dissipation.

\section{Conclusion}

The classification of the damping and energy consumption device is introduced, and the 
calculation model of a four stories RC frame for not installed viscous dampers each story installed dampers, the following two layers installed dampers and the above two layers installed dampers is found and simulated using sap2000.

1) The interlayer displacement, angular displacement and interlayer shear force between layers of the floors is significantly decreased on each floor of frame structure with viscous dampers, and can effectively improve the seismic resistance of frame structure, consume the earthquake energy, improve the seismic performance of structures

2) Install the viscous dampers in the frame structure that make the joint produce stress concentration, so the joints need to be strengthened. But the internal force of the beam end and column end in the joint decreases obviously, the internal force in the joints are effectively improved.

3) The uniform arrangement of viscous dampers in the frame structure can better play the damper's energy dissipation capacity, and the frame structure has a higher safety reserves at the same time.

\section{Acknowledgement}

In this paper, this research was financially supported by Scientific and Technical Research Foundation for Young Scientist of the Higher Education Institutions of Hebei Province (QN2014119).

\section{References}

[1] Morgen B, Kurama Y.A friction damper for posttensioned precast concrete moment Frames[J]. PCI Journal,2004,49( 4) : 112-133.

[2] Zhou Yun, Yin Qingli, Lin Shaoming. Experimental investigation on seismic performance of $\mathrm{RC}$ frame structures with viscous damper energy dissipation haunch braces [J], Journal of building structures, 2011,11(32): 64-73.

[3] Cui Mingjuan, Shao Yong. Hysteretic Performance of Beam to column joints with slit dampers static strength of concrete filled tubular flange girders with corrugated weds $[\mathrm{J}]$, Journal of Yantai university, 2012, 25 (3) : 205-211.

[4] Qing Jiang ,Xinzheng Lu, Hong Guan,Xianguo Ye. Shaking table model test and FE analysis of a reinforced concrete mega-frame structure with tuned mass dampers[j]. The Structural Design of Tall and Special Buildings,2014,23(18):1426-1442

[5] Hejazi, F , Zabihi, Jaafar, M. S, Development of elasto-plastic viscous damper finite element model for reinforced concrete frames [J].soil dynamics and earthquake engineering 65(10): 284-293.

[6] Zhou Y, Lu X Y, Weng D G, et al. A practical design for reinforce concrete structures with viscous damper $[\mathrm{J}]$.Engineering structures, 2012,(39): 187-198. 